\title{
Public Stigma on Depression Comorbid with Diabetes: A Vignette-Method Study in China
}

Patrick Leung ( $\square$ pleung@uh.edu )

University of Houston

Robin E. Gearing

University of Houston

Wanzhen Chen

East China University of Science and Technology

Monit Cheung

University of Houston

Kathryne B. Brewer

University of New Hampshire

Xiao Li

East China University of Science and Technology

Xuesong He

East China University of Science and Technology

\section{Research Article}

Keywords: Public stigma, Diabetes-associated depression, Family stress, Anti-stigma, Experimental Vignettes

Posted Date: December 10th, 2021

DOI: https://doi.org/10.21203/rs.3.rs-1115277/v1

License: (c) (1) This work is licensed under a Creative Commons Attribution 4.0 International License.

Read Full License 


\section{Abstract}

Background: Depression and diabetes are common illnesses affecting individuals with health challenges and family stress. Research suggested stigma-reduction interventions for families facing health-related stressors. This study examined factors predicting public stigma on depression alone or comorbid with diabetes.

Methods: In Shanghai, China, consented respondents to a community-based survey read one of four vignettes varied by depression types and gender of the Vignette Subject (VS). This vignette method measures each respondent's Individualized Public Stigma score, attitude toward the subject's family with the Devaluation of Consumer's Families score, and problem seriousness leading to stress.

Results: 125 respondents expressed views on depression or diabetes-associated depression via their answers to a randomly assigned vignette. Results show significant associations with Individualized Public Stigma when entering the regression model with five variables: problem seriousness, knowing someone with a mental health problem, subject's gender, attitude toward the subject's family, and depression comorbid with diabetes. Regression statistics showed that a person's Individualized Public Stigma scores could be predicted by two of these variables: perceived problem seriousness and sympathy toward the affected family. Yet, comorbidity with diabetes was not a significant predictor of stigma.

Conclusions: This study concludes that the cultural value toward community support could be an educational means to help the public realize the importance of protecting the families affected by mental health stigma. Applying this theory in action, practitioners must assess how self-stigmatization interfaces with the public perception of the patient's family. In addition, when people have a highly sympathetic attitude toward the patient's family and perceive the presenting problem as severe, they must be aware of the impact of individualized stigma on the patient. Future research must focus on these cultural perspectives to support early anti-stigma interventions.

\section{Background}

Both depression and diabetes are major global public health concerns. In China, the reported prevalence rates of these two illnesses have been drastically increasing. In terms of depression, a cross-sectional epidemiological survey of the prevalence of mental disorders among 32,552 respondents revealed that depressive disorders were the second most common class of disorders in China both in the 12 months before the interview (weighted prevalence $3.6 \%, 3.0-4.2 \%$ ) and in a lifetime (6.8\%, 5.8-7.8\%) [1]. Females $(4.2 \%, 3.4-4.9 \%)$ had a higher prevalence than males $(3.0 \%, 2.3-3.7 \%)$ in the 12 months before the interview; however, there was no significant difference between rural $(3.7 \%, 3.0-4.5 \%)$ and urban $(3.4 \%$, $2.7-4.2 \%$ ) areas [1]. In terms of diabetes, a nationally representative sample of 75,880 participants found that the weighted prevalence of total diabetes, self-reported diabetes, newly diagnosed diabetes, and prediabetes were $12.8 \%, 6.0 \%, 6.8 \%$, and $35.2 \%$, respectively [2]. However, few studies reported how a 
better understanding of depression and its health connections might lessen the public stigma toward health-associated depression. This study aims to use a set of vignettes to explore Chinese people's perceptions toward families affected by depression and diabetes-associated depression.

\section{Comorbidities of Diabetes and Depression}

Depression and diabetes frequently occur together, and diabetes-associated depression can increase the risk of severe complications and mortality $[3,4,5]$. A recent meta-analysis found comorbid depression occurring in approximately one out of four adults with Type 2 diabetes [6]. These increased rates of depressive disorders in adults with Type 1 and Type 2 diabetes range from 8-15\% worldwide [7]. In China, a meta-analysis found $27 \%$ of individuals with Type 2 diabetes also had depression, $20 \%$ had mild depression, and $10 \%$ had moderate to severe depression [8]. A growing body of research indicates the relationship between depression and diabetes is bidirectional, wherein individuals with diabetes are twice as likely to develop depression and, conversely, those experiencing depression are at a heightened risk for diabetes $[9,10,11,12]$. A prospective longitudinal study conducted with 17,708 participants across 28 provinces of China found that participants with depressive symptoms at the baseline were $33 \%$ more likely to develop Type 2 diabetes, and those with baseline diabetes were at a 35\% increased risk of developing persistent depressive symptoms [12]

Other research examined gender differences in individuals with depression comorbid with diabetes. Sun and colleagues [13] studied rates of depression in 229,047 adults with diabetes in China and found a $4.8 \%$ prevalence of subthreshold depression (male, 3.6\%; female, $5.5 \%$ ) and $1.1 \%$ prevalence of probable depression (male, $0.8 \%$; female, $1.3 \%$ ). Five years later, high depression rates occurred among females (32\%) and males (26\%) with Type 2 diabetes [8]. Those with both illnesses represent a population in need of mental and health care.

\section{Why Studying Mental Health Stigma in China}

In Shanghai, Wang et al [14] studied factors associated with depression and Type 2 diabetes in 865 Chinese older adults. Results found that individuals with employment, higher salary, and at least a college education exhibited more depressive symptoms than their less financially stable and lower educated counterparts [14]. These findings may lead to research connecting depression and diabetes to job satisfaction and work-life balance in various working environments. In Hong Kong, Tung et al [15] examined psychological comorbidities among Chinese adults with Type 1 diabetes. They found that the higher rate of depression could be due to lifestyle adaptations to diabetes, lack of social interactions, and feelings of losing control of life events due to medical necessities. In Taiwan, Huang et al [1] compared treatment utilization between 1,209 patients with Type 2 diabetes (T2DM) and major depressive disorder (MDD) and 12,090 patients with T2DM but no MDD. They found that the MDD group had $23.43 \%$ more non-psychiatric outpatient visits than the non-MDD group. Additionally, they found that while women utilized healthcare services more often, men had 0.82 times more hospitalizations, indicating that more routine treatment-seeking behaviors can prevent hospitalizations [1]. These studies demonstrated a need 
to study the comorbidity between mental health (depression) and health (diabetes), which often results in public stigma by the affected individual and their families.

\section{Study Framework}

The Chinese Lay Theory [16] is used as the explanation base to address the association between the fundamental Chinese values and three types of stigmatization.

The first type is self-stigmatization. Chinese beliefs emphasize the importance of whole-body harmony and self-support, but research on mental illness varies significantly in findings of etiology and stigma [17]. Pan et al [18] analyzed the content in a popular social media site in China and found about 16,000 depression-related posts pointing to depression as a controllable disease by the patient. $\mathrm{Ng}$ et al [19] investigated Chinese mothers with adolescent children and found that these mothers placed high importance on children's self-improvement, believing they could help their children fight against depression. This self-control concept is contrary to the expected images of the patients with depression that they cannot control themselves but may harm or threaten others. These images caused a conflict between weak and potential social threats $[20,21]$.

Second is the stigma against the family, which is a less examined stigma connecting to illness severity and caregiver stress. In Hong Kong, Lee et al [22] found that Chinese patients with schizophrenia were more likely to anticipate being stigmatized, conceal their health condition, and default on clinic visits than patients with diabetes. Their focus was not to compare depression with diabetes. Still, it brought about the unwelcome disclosure of a mental health illness, workplace difficulties, family rejection, and treatment non-adherence when patients dealt with life stress. The severity of the disease is also related to the use of psychotropic drugs. In a Hong Kong study, 83 practicing psychiatrists reported that people were wary of seeking help for depression because of medication side effects, such as confusion and being "muddleheaded" with high stress [23, p.1].

The third is public stigma. Depression is perceived as an uncontrollable disease that can cause shame and guilt, regardless of education, IQ, or income; thus, patients must undertake routine assessments for their health management [24, 25]. In a 2013 study when depression and diabetes were co-present, 89\% of the public in China had a negative stigma of depression; in comparison, only $32 \%$ had a negative stigma of diabetes as measured by a devaluation instrument [26]. Even though the patient's physical symptoms are not as stigmatized as psychiatric symptoms, shame is a psychological barrier against help-seeking [27]. Yeung et al [28] highlighted that Chinese men who lived with a 'mentally ill' label had a very high level of mental distress. In their study, common themes of a mental illness encounter included: mental health problems, shameful business, topics prohibited to discuss outside of the family, stress avoidance, refusal to seek outside help, the need to consult natural healers, reliance on family resources, seeking help from medical practitioners, and noticing sudden behavioral changes. Family members reported seeking help only when the patient was out of control [28]. Social avoidance was a widely used family strategy to avoid stigma. 
These three types of stigmatization can intersect with the labels used in medical diagnoses. To avoid being labeled, families prefer healthcare to other kinds of treatment. Wang et al [29] found that Chinese individuals who had a high perception of stigmatization had a higher likelihood of manifesting depression as a somatic complaint, which would be an acceptable reason to seek medical care. Additional Chinese studies focused on self-stigma toward depression as the illness is related to dysfunctional attitude and maladaptive cognitive coping [30], self-efficacy and social avoidance [31, 32], and stigma-reduction interventions [33]. More negative stigma is associated with an illness when the patient shows severe psychiatric symptoms.

The above studies supported the current study for investigating public stigma toward the individuals who have been diagnosed with depression only or comorbid with diabetes. Study results will contribute to antistigma programs incorporated with cultural perspectives. Specifically, this study addressed three research questions:

1. Does gender affect public stigma against a patient's depression?

2. Does depression comorbid with diabetes influence public stigma toward depression?

3. Among Chinese individuals, what characteristics could predict a high public stigma toward a patient with depression?

\section{Methods}

This study used a community survey designed with four experimental vignettes to examine whether depression alone or comorbid with diabetes could lead to a higher level of public stigma toward the Vignette Subject (VS). In 2018, the team administrated an anonymous survey to a convenience sample drawn from the general public in Shanghai, China. The Institutional Review Board (IRB) approved the human subject protection procedures at the first author's affiliated university.

\section{Sampling and Data Collection}

After a series of research training, 24 Mandarin-speaking Research Assistants (RAs) from the last author's affiliated university collected data for three months in 2018. Using a convenience sampling method, they recruited subjects from various public places in Shanghai, including office buildings, cinemas, restaurants, public squares, parks, metro stations, shopping malls, markets, bookstores, universities, beauty salons, and hospitals. Inclusion criteria included adults (18 years or older) currently residing in Shanghai who could speak Mandarin. The survey was self-administered or read to the respondent by the RA. Before asking further questions related to depression, the RA assigned a random vignette to each consented participant (detailed under Measures). This vignette method has proven efficacy in studying attitudes, perceptions, and opinions related to mental health and childhood issues $[34,35,36]$.

Respondents received 50 Renminbi (RMB, Official currency in mainland China) (equivalent to US\$7) as an incentive for filling out this 40 -minute survey.

\section{Measures}


The first section of the survey contained questions on the respondent's age, gender, marital status, education level, employment and financial situation, number of children, monthly income, and ability to speak the local dialect. It also asked about their residence status with three questions: residence location (urban or rural), hukou (official residence registration) at birth, and current hukou. The respondents also answered whether they knew someone with a mental health problem ( $0=\mathrm{No} ; 1=\mathrm{Yes})$.

The variable 'Attitude toward the Patient's Family' estimated family stress with the 7-item Devaluation of Consumer Families (DCF) scale, ranging from 0 (no stigma) to 3 (highest stigma) (Cronbach's a $=.77$, [37]). A 4-point Likert-type scale rated the DCF score for calculating the mean of the items:(a) be friends with the patient's relatives; (b) believe in the care provided by the patient's parents; (c) treat the patient's family with no biases; (d) visit the family with a member hospitalized due to a severe mental illness; (e) treat families with or without mental illness problems equally; (f) not blame the patient's parents; $(\mathrm{g})$ be a visitor to the patient's family. The higher this devaluation score, the higher stress the family has experienced.

In the second section of the survey, each respondent read one of four vignettes varied by the VS's gender (male or female) and the illness type (depression only or comorbid with diabetes): (1) a male with depression; (2) a female with depression; (3) a male with diabetes-associated depression; and (4) a female with diabetes-associated depression. Those who answered questions based on the assigned vignette of the VS with depression and diabetes received a score of 1 in the variable 'Comorbid with Diabetes.' Respondents assessed the presenting problem in the vignette based on a 'problem seriousness' rating scale from 1 to 10 (10 being the most serious).

There was also a 14-item Stigma Scale concerning the VS, from 1 to 7, with 1=low stigma and 7=high stigma (see Table 1). The reliability of the Stigma Scale was acceptable (Cronbach a =.79). The higher the score, the higher the stigma toward depression or depression-associated health problems.

\section{Factor Analysis}

Factor analysis using the principal component method with varimax rotation helped group the concepts for more accurate interpretations [38]. Recent literature on social stigma also recommends using factor analysis to identify appropriate measures to explore depression-related stress factors for examining the impact of health stigma on work productivity [39]. In this study, an eigenvalue of 1 or higher and the Scree plot determined factor extractions. The factor loading of .50 or higher was the criterion for item inclusion under each extracted factor [38]. Table 1 shows that, among 14 items on the Stigma Scale, the final three factors were: Factor 1 (Individualized Public Stigma) with items (1) to (6); Factor 2 (Probable Change) with items (7) to (11); and Factor 3 (Community Stigma) with items (12) to (14). A Kaiser-Meyer-Olkin (KMO) score of .80 verified that the sampling adequacy with these 14 items was acceptable for further analyses.

\section{Results}




\section{Respondent Characteristics}

Table 2 summarizes the characteristics of 125 respondents who completed the survey. Among them, $51 \%$ were female, and $49 \%$ were male. Over $60 \%$ were married, and $36 \%$ were single. On average, these respondents were about 38 years old (Standard Deviation $(S D)=14.78$ ), ranging from 18 to 78 years of age. Most of them had one child (mean=1.38, $S D=.59$ ). More than half of them (58.4\%) had a college education or higher. Among these respondents, $56 \%$ had employment, but $44 \%$ were not employed. About $35 \%$ had a monthly income of RMB 3,000-5,999, comparable to a typical Shanghainese's monthly earning earned about RMB 5,348 monthly in 2018 [40]. About 42\% indicated that they had a break-even financial situation. The majority (83\%) lived in the urban area, but only $58 \%$ possessed an urban hukou as many were still processing their urban residence. More than half (55\%) could speak Shanghainese (the local dialect in this city). About $49 \%$ would seek help when facing a mental health problem, while $11.2 \%$ had personally experienced a mental health problem. The analysis compared respondents by the VS's gender ( $0=$ male vignette; $1=$ female vignette) and the presenting problem ( $0=$ depression only; $1=$ depression comorbid with diabetes).

\section{Predicting Public Stigma}

Three standard multiple regression (MR) models analyzed predictive variables on the three "Public Stigma" factors: (1) Individualized Public Stigma, (2) Probable Change, and (3) Community Stigma. We checked all assumptions for multiple regression analyses. Only the Individualized Public Stigma factor score achieved statistical significance, but not Probable Change or Community Stigma. As a result, the Individualized Public Stigma factor score was used as the dependent variable in the final MR model, with positive scores meaning a low stigma level and negative scores indicating a high stigma level. The operationalized definition of "Individualized Public Stigma" was a person's attitude towards someone with mental illness as less likely to be accepted in friendship, employment, marriage, or school affiliation and more likely to be found in violence and law troubles.

The final MR model (Table 3) produced results significantly associated the Individualized Public Stigma score with the entry of five variables: problem seriousness, knowing someone with a mental health problem (MHP), VS's gender, attitude toward the VS's family, and comorbid with diabetes $[F(5,89)=11.652$, $P<.001]$. These factors account for about $40 \%$ of the variance to explain Individualized Public Stigma. Specifically, when the respondents perceived the presenting problem as more serious (i.e., a higher score) $(t=6.172, P<.001)$ and had a positive attitude toward the VS's family (i.e., a lower score) $(t=2.529, P=.013)$, they tend to have a higher level of public stigma. However, three other variables (VS's gender, knowing someone with an MHP, and comorbid with diabetes) did not show a significant $P$ value in the overall model.

The results did not support research questions 1 and 2. The interpretations were (1) the Individualized Public Stigma score toward a patient with depression did not significantly differ whether the patient is male or female, and (2) the VS's diabetes-associated symptoms do not change the respondent's Individualized Public Stigma score toward depression. For question 3, none of the personal 
characteristics of the respondents were significant predictors of Individualized Public Stigma. In this multivariate analysis, the public tends to show a higher public stigma toward the VS when assessing depression (with or without diabetes) as a more severe problem and having a more positive attitude toward the VS's family. The Chinese Lay Theory supports this finding that the family's face concern ("mianzi") is a self-stigma source interacting with an individual member's mental health illness $[41,42]$.

\section{Discussion}

Based on literature and current data from this study, the following discussion addresses two significant public stigma predictors and three non-significant results. In a systematic review of 41 studies in the Pacific Rim region, Ran et al [43] found that cultural factors led to the stigma of mental illness.

Specifically, Chinese people who are collectivist-oriented believe that mental illness is equivalent to secrecy, internalizing it with self-stigma but accepting "one's role as handed down by destiny" [16 p. 38].

Regarding the two significant predictors, first, increased problem seriousness is associated with increased public stigma. This finding aligns with existing research showing individuals report higher mental health stigmatization toward conditions typically viewed as severe (e.g., schizophrenia, psychosis) [44, 45]. This study found that the respondents assessed the presenting problem with a moderately severe score (Mean=6.37 on a 10-point scale). This average score implies if the public underestimates the severity of a mental health problem, they would desire anti-stigma interventions to reduce the negative effect of the illness [46]. Based on the Chinese Lay Theory, after seeking treatment, a patient's family felt it essential to have community education to help correct public misconceptions [16].

Second, having a positive attitude toward the family of the VS with depression tends to hold a higher public stigma. This person-community relationship provides two potential implications from both individual and cultural perspectives. Individually, there is a sympathy connection. Yang et al [47] found a similar link between general stigma and individualized stigma. People who have a biased attitude toward a mental illness expect the patient's family not to feel comfortable in social events. However, The Chinese lay value suggests sympathy with the family a social-desirability connection, which captures the communal aspect of Chinese culture and its emphasis on the family unit over the individual [16]. With this social-desirability consideration, people might not admit having a negative attitude toward the family

with a member suffering from a mental health problem, regardless of its connection to diabetes (as the comorbidity variable is not significant). This reverse stigma phenomenon is associated with the community's desire to balance individual stigma and family concern perceptions. In this study, the respondents maintained a personal value that mental illness is not acceptable while protecting the family from being labeled.

In terms of non-significant factors, this study did not find the VS's gender a significant predictor of public stigma toward individuals with depression. Previous studies identified an association between gender and stigma toward treating mental disorders. In a large city project, Yang et al [47] found that Chinese men as respondents had a higher personal stigma than Chinese women toward depression as a disorder. 
In another study involving Asian college students, men had a more increased public stigma than women toward accessing mental health treatment [48]. However, in this study, the gender of the VS, but not of the respondents themselves, did not predict the respondents' public stigma level toward depression. Based on the Chinese Lay Theory, depression as misfortune could overshadow one's perception of stigmatization.

Another explanation of the non-significant findings was related to educational information about diabetes-associated depression. Most respondents were middle-aged, and over half (52.8\%) were employed full-time. Even though the sample came from a large metropolitan city, one-third (33.6\%) had a rural hukou at birth. These demographics suggest the findings might come from a cohort with little formal education about mental health or caregiver stress stemming from an individual's illness.

Third, almost half (48.8\%) of the respondents personally knew someone with mental health problems, but fewer $(11.2 \%)$ reported experiencing a mental health issue. Previous research found that knowing someone with a mental health disorder could influence one's perception [44, 49]. Similarly, lower stigma toward depression occurred among people with greater exposure to individuals experiencing mental illness [44]. In a random sample of the general public in Shanghai, Zheng [49] also found people with frequent and close contact with someone with mental illness had less stigma. On the contrary, in an online survey conducted in China, $\mathrm{Li}$ et al [50] found no relationship between contact levels and the mental illness stigma toward people with mental disorders. These mixed reviews support early learning through case studies to reduce stigma toward mental illness [51]. The Chinese Lay Theory also suggests collecting qualitative data from contemporary families regarding their views towards individuals with mental illness [16].

This study has limitations. One limitation was its convenience sampling method, although reaching potential subjects in diverse locations was a recruitment strategy. A second limitation was that those with a higher-than-average education level proportionally over-represented the respondents. A third limitation was that most respondents had only one child, a unique demographic characteristic due to the country's one-child policy for 34 years between 1980 and 2014. Nevertheless, this study provided data representative of the opinions from both one-child parents (representing respondents mainly from urban areas) and parents with two or more children (representing migrant parents from rural areas).

Most health insurance schemes in China do not cover mental health services [52, 53]. Gao et al [54] used survey data to attest to the challenges among Chinese people, especially the migrant populations, who do not disclose or admit their mental health diagnoses because psychiatric treatment means costly hospitalization. This current study identifies the need in this area to support primary-care providers who promote mental health services by normalizing psychiatric and psychological medical treatment and educating patients and their families. This treatment suggestion is in line with a folk value of Chinese

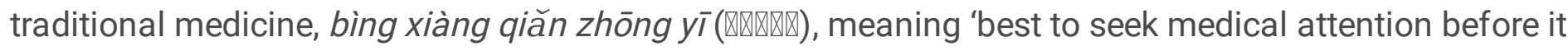
takes a hold' (our translation). It implies early mental health treatment could reduce family stress and 
expenses. Early education also means more deliveries of health-associated education of depression for effectively reducing stigmatization of oneself (the patient) and others (the family).

\section{Conclusions}

Significant results supported the third research question of this study investigating what characteristics among Chinese individuals could help understand the public stigma toward depression. This support implies that effective public education could help patients with internal and external stressors due to mental health issues. A considerable model shows that Individualized Public Stigma was associated with five variables: problem seriousness, knowing someone with a mental health problem, the affected individual's gender, attitude toward the patient's family, and diabetes-connected depression. In this model, problem seriousness and attitude toward the patient's family were significant predictors of Individualized Public Stigma. Future research should examine the interaction effect between health and mental health on a community's view toward mental health diagnoses. Specifically, data to be collected from a community-based assessment of knowledge and attitude toward patients with depression must include building a support system for the affected family, not only the patient. A potential research question may help support early anti-stigma interventions: What interaction effect may occur between a patient's selfstigmatization toward mental health symptoms of depression and the community's willingness to help the patient's family? Answers will help practitioners help families with psychological distress and thus prevent health problems from being more severe.

\section{Abbreviations}

DCF: Devaluation of Consumer Families

IRB: Institutional Review Board

KMO: Kaiser-Meyer-Olkin

MDD: Major Depressive Disorder

MHP: Mental health problem

MR: Multiple Regression

RA: Research Assistant

RMB: Renminbi, official currency of mainland China

SD: Standard deviation

T2DM: Type 2 diabetes

VS: Vignette Subject 


\section{Declarations}

Ethics Approval and Consent to Participate: This study received ethical and IRB approval in China and the United States. Since this was an anonymous survey, a consent waiver letter was provided to all survey participants.

Consent for Publication: All authors have consented to submit this manuscript to this journal for possible publication.

Funding: The authors did not receive funding from external sources.

Availability of Data and Materials: Data and other unlisted materials are not available to the public.

Competing Interests: The authors report no conflicts of interest in conducting, implementing, or publishing this study.

Authors' Contributions: PL wrote the main manuscript text and ran statistical analyses. REG was responsible for research methodology, vignette design, training materials, team coordination, and editorial support. MC and KBB prepared the SPSS files, formatted and validated figures, and provided editorial support. $\mathrm{WC}, \mathrm{XL}$, and $\mathrm{XH}$ contributed time and effort in training research assistants and collecting data. This research team contributed to the study's research design and literature reviews and participated in the entire research process from conceptualization to final report preparation.

Acknowledgements: The team wants to thank the journal board and staff for their comments and editorial support.

\section{References}

1. Huang CJ, Lin $\mathrm{CH}$, Hsieh HM, Chang CC, Chu CC, Sun DP, et al. A longitudinal study of healthcare utilisation and expenditure in people with Type 2 diabetes mellitus with and without major depressive disorder. Gen Hosp Psychiatry. 2019;57:50-58.

https://doi.org/10.1016/j.genhosppsych.2018.09.007

2. Li Y, Teng D, Shi X, Qin G, Qin Y, Quan H, et al. Prevalence of diabetes recorded in mainland China using 2018 diagnostic criteria from the American Diabetes Association: national cross-sectional study. Br Med J. 2020;369. https://doi.org/10.1136/bmj.m997

3. Katon WJ, Russo JE, Heckbert SR, Lin EH, Ciechanowki EL, Young, B, et al. The relationship between changes in depression symptoms and changes in health risk behaviors in patients with diabetes. Int J of Geriatr Psychiatry. 2010;25:466-475. https://doi.org/10.1002/gps.2363

4. Moussavi S, Chatterji S, Verdes E, Tandon A, Patel V, Ustun B. Depression, chronic diseases, and decrements in health: results from the World Health Surveys. Lancet. 2007;370(9590):851-858. https://doi.org/10.1016/S0140-6736(07)61415-9 
5. Sartorius N. Depression and diabetes. Dialogues Clin Neurosci. 2018;20(1):47-52. https://doi.org/10.31887/DCNS.2018.20.1/nsartorius

6. Khaledi M, Haghighatdoost F, Feizi A, Aminorroaya A. The prevalence of comorbid depression in patients with Type 2 diabetes: an updated systematic review and meta-analysis on a huge number of observational studies. Acta Diabetol. 2019;56:631-650. https://doi.org/10.1007/s00592-019-012959

7. Holt RI, DeGroot M, Lucki I, Hunter CM, Sartorius N, Golden SH. NIDDK international conference report on diabetes and depression: current understanding and future directions. Diabetes Care. 2014;37(8):2067-2077. https://doi.org/10.2337/dc13-2134

8. Liu XB, Zhang HL, Li YX, Zhong DL, Li J, Jin RJ. The detection rate of depression in Chinese with Type 2 diabetes mellitus: a meta-analysis. Chinese J Evid Based Med (Chinese).2020;20(8):930-937.

9. Alzoubi A, Abunaser R, Khassawneh A, Alfaqih M, Khasawneh A, Abdo N. The bidirectional relationship between diabetes and depression: A literature review. Korean J Fam Med. 2018;39:137146.

10. Katon WJ. The comorbidity of diabetes mellitus and depression. Am J Med. 2008;121(11 Suppl 2):S8-S15. https://doi.org/10.1016/j.amjmed.2008.09.008

11. Mezuk B, Eaton WW, Albrecht S, Golden SH. Depression and Type 2 diabetes over the lifespan A meta-analysis. Diabetes Care. 2008;31(12):2383-2390. https://doi.org/10.2337/dc08-0985

12. Zhao F, Pan A, Yang X, Meng R, Ye Y, Wang Y, et al. Bidirectional association between depressive symptoms and Type 2 diabetes mellitus: The China Health and Retirement Longitudinal Study. J Diabetes Complications. 2019;33(10):107387. https://doi.org/10.1016/j.jdiacomp.2019.05.018

13. Sun JC, Xu M, Lu JL, Bi YF, Mu YM, Zhao JJ, et al. Associations of depression with impaired glucose regulation, newly diagnosed diabetes and previously diagnosed diabetes in Chinese adults. Diabet Med. 2015;32(7):935-943. https://doi.org/10.1111/dme.12649

14. Wang L, Song R, Chen Z, Wang J, Ling F. Prevalence of depressive symptoms and factors associated with it in Type 2 diabetic patients: a cross-sectional study in China. BMC Public Health. 2015a;15(1). https://doi.org/10.1186/s12889-015-1567-y

15. Tung KY, Cheng KS, Lee WK, Kwong PK, Chan KW, Law ACB, et al. Psychiatric morbidity in Chinese Adults with type 1 diabetes in Hong Kong. East Asian Arch Psychiatry. 2015;25(3):128-136.

16. Lam CS, Tsang HWH, Corrigan PW, Lee YT, Angell B, Shi K, et al. Chinese Lay Theory and mental illness stigma: implications for research and practices. J Rehabil. 2010;76(1):35-40.

17. Gu Y, Hu J, Hu Y, Wang J, Gu Y, Hu J, et al. Social supports and mental health: A cross-sectional study on the correlation of self-consistency and congruence in China. BMC Health Serv Res. 2016;16:1-7. https://doi.org/10.1186/s12913-016-1463-x

18. Pan J, Liu B, Kreps GL. A content analysis of depression-related discourses on Sina Weibo: Attribution, efficacy, and information sources. BMC Public Health. 2018;18(1):772. https://doiorg.ezproxy.lib.uh.edu/10.1186/s12889-018-5701-5 
19. Ng J, Xiong Y, Qu Y, Cheung C, Ng FF, Wang M, et al. Implications of Chinese and American mothers' goals for children's emotional distress. Dev Psychol. 2019;55(12):2616-2629. https://doiorg.ezproxy.lib.uh.edu/10.1037/dev0000834

20. Du KW. News discourse research on depression reported by Sina.com(Chinese) [dissertation of master's degree in medicine].China: Henan University; 2019.

21. Pang DN. Research on "depression" discourse in plain media reports in east China (Chinese) [dissertation of master's degree]. China: Communication University of Zhejiang; 2019.

22. Lee $S$, Chiu MY, Tsang A, Chui H, Kleinman A. Stigmatizing experience and structural discrimination associated with the treatment of schizophrenia in Hong Kong. Soc Sci Med. 2006;62(7):1685-1696. https://doi.org/10.1016/j.socscimed.2005.08.016

23. Sun KS, Lam TP, Lam KF, Lo TL. Barriers and facilitators for psychiatrists in managing mental health patients in Hong Kong - Impact of Chinese culture and health system. Asia Pac Psychiatry. 2018;10(1). https://doi.org/10.1111/appy.12279

24. Guo H, Wang X, Mao T, Li X, Wu M, Chen J. How psychosocial outcomes impact on the self-reported health status in Type 2 diabetes patients: Findings from the Diabetes Attitudes, Wishes and Needs (DAWN) study in eastern China. PLoS ONE. 2018;13(1):1-13. https://10.1371/journal.pone.0190484

25. Li J, Zhang MM, Zhao L, Li WQ, Mu JL, Zhang ZH. Evaluation of attitudes and knowledge toward mental disorders in a sample of the Chinese population using a web-based approach. BMC Psychiatry.2018;18:367-374.

26. Chen L, Gao Y, Zhai JG, Cao MH, Chen M, Ji F, et al. A comparative study of public stigma of depression and diabetes. Chinese Journal of Behavioral Medicine and Brain Science (Chinese). 2013;22(5):423-424.

27. Jaacks LM, Liu W, Ji L, Mayer-Davis EJ. Type 1 diabetes stigma in China: A call to end the devaluation of individuals living with a manageable chronic disease. Diabetes Res Clin Pract. 2015;107(2):306-307. https://doi.org/10.1016/j.diabres.2014.12.002

28. Yeung $\mathrm{E}$, Irvine $\mathrm{F}, \mathrm{Ng} \mathrm{SM}$, Tsang $\mathrm{K}$. How people from Chinese backgrounds make sense of and respond to the experiences of mental distress: thematic analysis. J Psychiatr Ment Health Nurs. 2017;24(8):589-599. https://doi.org/10.1111/jpm.12406

29. Wang X, Peng S, Li H, Peng Y. How depression stigma affects attitude toward help seeking: The mediating effect of depression somatization. Soc Behav Pers. 2015b;43(6),945-954.

30. Xue X. The relationship between stigma of depression and cognitive coping strategies and therapeutic research (Chinese) [dissertation of master's degree in medicine]. China: Jining Medical University; 2017

31. Xiao SJ. Research on the relationship among college students' mental illness stigma, self-efficacy and professional psychological help-seeking attitude (Chinese) [dissertation of master's degree]. China: Sichuan Normal University; 2017.

32. Zhang JL. The relationship between depression, self-stigma, self-efficacy, and social avoidance(Chinese) [dissertation of master's degree]. China: Henan University; 2011. 
33. Xu Q, Jiang YB, Tang YP, Hu MY, Cheng ZH. Study about the clinical effect of stigma intervention on the rehabilitation process for patients with depression. China Modern Doctor. 2014;52(22):82-85.

34. Coles ME, Heimberg RG, Weiss BD. The public's knowledge and beliefs about obsessive compulsive disorder. Depress Anxiety. 2013;30(8):778-785. https://doi.org/10.1002/da.22080

35. Gearing RE, MacKenzie MJ, Ibrahim RW, Schwalbe CS, Brewer KB. Stigma and mental health treatment of adolescents with depression in Jordan. Community Ment Health J. 2015;51(1):111-7. https://doi.org/10.1007/s10597-014-9756-1

36. Gearing RE, Brewer KB, Cheung M, Leung P, Chen W, He X. Suicide in China: community attitudes and stigma. OMEGA (Westport).2021 https://doi.org/10.1177/0030222821991313

37. Struening EL, Perlick DA, Link BG, Hellman F, Herman D, Sirey JA. Stigma as a barrier to recovery: the extent to which caregivers believe most people devalue consumers and their families. Psychiatr Serv. 2001;52(12):1633-1638. https://doi.org/10.1176/appi.ps.52.12.1633

38. Tabachnick B, Fidell L. Using multivariate statistics (7 $7^{\text {th }}$ Ed.). Pearson; 2019.

39. Martin AJ, Giallo R. Confirmatory factor analysis of a questionnaire measure of managerial stigma towards employee depression. Stress Health.2016;32(5):621-628. https://doi.org/10.1002/smi.2655

40. Shanghai Statistical Yearbook. Basic statistics of income and expenditure of residents (2015-2018). 2019. http://tj.sh.gov.cn/tjnj/20200427/4aa08fba106d45fda6cb39817d961c98.html

41. Cheung M, Leung P, Chen W, Gearing RE, Brewer KB, Chen X, et al. Public stigma on substance users in China. J Subst Use. 2021

42. Mak W, Cheung R. Psychological distress and subjective burden of caregivers of people with mental illness: the role of affiliate stigma and face concern. Community Ment Health J.2012;48(3):270-274. https://doi.org/10.1007/s10597-011-9422-9

43. Ran MS, Hall BJ, Su TT, Prawira B, Breth-Petersen M, Li XH, et al. Stigma of mental illness and cultural factors in Pacific Rim region: a systematic review. BMC Psychiatry. 2021;21(1),1-16. https://doi.org/10.1186/s12888-020-02991-5

44. Lee EH, Hui CL, Ching EY, Lin J, Chang WC, Chan SK, et al. Public stigma in China associated with schizophrenia, depression, attenuated psychosis syndrome, and psychosis-like experiences. Psychiatr Serv. 2016;67(7):766-770. https://doi.org/10.1176/appi.ps.201500156

45. Reavley NJ, Jorm AF. Stigmatizing attitudes towards people with mental disorders: findings from an Australian National Survey of Mental Health Literacy and Stigma. Aust N Z J Psychiatry. 2011;45(12),1086-1093. https://doi.org/10.3109/00048674.2011.621061

46. Subica AM, Aitaoto N, Sullivan JG, Henwood BF, Yamada AM, Link BG. Mental illness stigma among Pacific Islanders. Psychiatry Research. 2019; 273:578-585. https://doi.org/10.1016/j.psychres.2019.01.077

47. Yang F, Yang BX, Stone TE, Wang XQ, Zhou Y, Zhang J, et al. Stigma towards depression in a community-based sample in China. Compr Psychiatry. 2020;97:152152. https://doi.org/10.1016/j.comppsych.2019.152152 
48. Pedersen ER, Paves AP. Comparing perceived public stigma and personal stigma of mental health treatment seeking in a young adult sample. Psychiatry Res. 2014;219(1):143-150. https://doi.org/10.1016/j.psychres.2014.05.017

49. Zheng H. Survey of mental illness stigma in a community population. Chinese J Public Health Management. 2015;31(3):410-412.

50. Li J, Zhang MM, Zhao L, Li WQ, Mu JL, Zhang ZH. Evaluation of attitudes and knowledge toward mental disorders in a sample of the Chinese population using a web-based approach. BMC Psychiatry.2018;18:367-374.

51. Flood-Grady E, Koenig Kellas J. Sense-making, socialization, and stigma: exploring narratives told in families about mental illness. Health Commun. 2019;34(6):607-617.

https://doi.org/10.1080/10410236.2018.1431016

52. Xian W, Xu X, Li J, Sun J, Fu H, Wu S, et al. Modeling hospitalization decision and utilization for the elderly in China. BMC Public Health. 2019;19(1):1-9. https://10.1186/s12889-019-7761-6

53. Zhou S, Huang T, Li A, Wang Z. Does universal health insurance coverage reduce unmet healthcare needs in China? Evidence from the National Health Service Survey. Int J Equity Health. 2021;20(1):117. https://doi.org/10.1186/s12939-021-01385-7

54. Gao J, Chu D, Ye T. (2021). Empirical analysis of beneficial equality of the basic medical insurance for migrants in China. Discrete Dyn Nat Soc. 2021:1-11. https://doi.org/10.1155/2021/7708605

\section{Tables}

Table 1 Factor analysis of stigma components 


\begin{tabular}{|c|c|c|c|c|}
\hline & $\begin{array}{l}\text { Individualized } \\
\text { Public Stigma }\end{array}$ & $\begin{array}{l}\text { Probable } \\
\text { Change }\end{array}$ & $\begin{array}{l}\text { Community } \\
\text { Stigma }\end{array}$ & $h^{2}$ \\
\hline $\begin{array}{l}\text { 1. How likely is it that you would allow [VS] to } \\
\text { be your friend? }\end{array}$ & .785 & .363 & -.083 & .755 \\
\hline $\begin{array}{l}\text { 2. How likely is it that you would hire [VS] to } \\
\text { work with you? }\end{array}$ & .770 & .375 & .026 & .734 \\
\hline $\begin{array}{l}\text { 3. How likely is it that you would allow [VS] to } \\
\text { marry your child? }\end{array}$ & .761 & .183 & -.039 & .614 \\
\hline $\begin{array}{l}\text { 4. How likely is it that you would accept [VS] } \\
\text { going to the same school as your child? }\end{array}$ & .723 & .257 & -.121 & .603 \\
\hline 5. Violent toward other people & -.632 & .006 & .109 & .411 \\
\hline 6. End up in trouble with the law & -.527 & .059 & .223 & .331 \\
\hline $\begin{array}{l}\text { 7. How likely is it that [VS] will be able to } \\
\text { change? }\end{array}$ & .048 & .848 & -.062 & .725 \\
\hline $\begin{array}{l}\text { 8. How likely is it that [VS] will be able to } \\
\text { change if } s / \text { he receives help? }\end{array}$ & -.055 & .776 & .127 & .621 \\
\hline $\begin{array}{l}\text { 9. How likely is it that [VS] will be respected in } \\
\text { the community? }\end{array}$ & .429 & .710 & .001 & .688 \\
\hline 10. Develop into a successful person & .415 & .680 & -.182 & .668 \\
\hline 11. How likely is it that [VS] will be happy? & .251 & .529 & .058 & .346 \\
\hline 12. Difficulty finding a job & -.101 & .018 & .899 & .819 \\
\hline 13. Difficulty making friends & -.032 & .024 & .870 & .580 \\
\hline 14. Difficulty finding someone to marry & .025 & -.065 & .758 & .579 \\
\hline Variance & 24.465 & 21.056 & 16.306 & 61.82 \\
\hline \multicolumn{5}{|c|}{$\begin{array}{l}\text { Note. [VS]=vignette subject or the patient with depression and diabetes-associated depression; } \\
\text { Extraction Method: Principal Component Analysis; Rotation Method: Varimax with Kaiser } \\
\text { Normalization; Varimax Rotation with KMO=.769 (Rotation converged in } 5 \text { iterations). }\end{array}$} \\
\hline
\end{tabular}

Table 2 Respondents' demographics $(n=125)$ 


\begin{tabular}{|c|c|c|}
\hline Variable & Frequency & $\%$ \\
\hline \multicolumn{3}{|l|}{ Vignette Condition } \\
\hline Male Vignette & 62 & 49.6 \\
\hline Female Vignette & 63 & 50.4 \\
\hline \multicolumn{3}{|l|}{ Vignette Presenting Problem } \\
\hline Depression only & 61 & 48.8 \\
\hline Depression with Diabetes & 64 & 51.2 \\
\hline \multicolumn{3}{|l|}{ Respondent's Gender } \\
\hline Male Respondent & 61 & 48.8 \\
\hline Female Respondent & 64 & 51.2 \\
\hline \multicolumn{3}{|l|}{ Marital status (\%) } \\
\hline Single & 45 & 36.0 \\
\hline Married & 76 & 60.8 \\
\hline Cohabitation & 1 & .8 \\
\hline Widowed & 1 & .8 \\
\hline No response & 2 & 1.6 \\
\hline \multicolumn{3}{|l|}{ Education } \\
\hline Did not complete High School & 3 & 2.4 \\
\hline High School grad & 36 & 28.8 \\
\hline Some college/trade & 37 & 29.6 \\
\hline BA or higher & 48 & 38.4 \\
\hline No response & 1 & .8 \\
\hline \multicolumn{3}{|l|}{ Employed } \\
\hline Not employed & 55 & 44.0 \\
\hline Part-time & 4 & 3.2 \\
\hline Full-time & 66 & 52.8 \\
\hline \multicolumn{3}{|l|}{ Monthly Income } \\
\hline$\leq 2999 \mathrm{RMB}$ & 30 & 24.0 \\
\hline $3,000-5,999 \mathrm{RMB}$ & 44 & 35.2 \\
\hline
\end{tabular}




\begin{tabular}{|c|c|c|}
\hline $6,000-8,999 \mathrm{RMB}$ & 28 & 22.4 \\
\hline$>9,000 \mathrm{RMB}$ & 14 & 11.2 \\
\hline No response & 9 & 7.2 \\
\hline \multicolumn{3}{|l|}{ Financial Circumstances } \\
\hline Can't Make Ends Meet & 9 & 7.2 \\
\hline I am barely Making it & 22 & 17.6 \\
\hline Breaking even & 53 & 42.4 \\
\hline I have extra money after bills & 22 & 17.6 \\
\hline I don't have to worry about money & 15 & 12.4 \\
\hline No response & 4 & 3.2 \\
\hline \multicolumn{3}{|l|}{ Current Residing Area } \\
\hline Urban & 104 & 83.2 \\
\hline Rural & 8 & 6.4 \\
\hline Suburban & 13 & 10.4 \\
\hline \multicolumn{3}{|l|}{ Hukou At Birth } \\
\hline Urban & 42 & 33.6 \\
\hline Rural & 82 & 65.6 \\
\hline No response & 1 & .8 \\
\hline \multicolumn{3}{|l|}{ Hukou Current } \\
\hline Urban & 72 & 57.6 \\
\hline Rural & 48 & 38.4 \\
\hline Transitioning Rural to Urban & 5 & 4.0 \\
\hline \multicolumn{3}{|c|}{ Local Dialect: Do you Speak Shanghainese? } \\
\hline Yes & 69 & 55.2 \\
\hline No & 54 & 43.2 \\
\hline No response & 2 & 1.6 \\
\hline \multicolumn{3}{|c|}{ Know someone with mental health problems } \\
\hline No & 58 & 46.4 \\
\hline Yes & 61 & 48.8 \\
\hline
\end{tabular}




\begin{tabular}{|lll|}
\hline No response & 6 & 4.8 \\
\hline Ever had a mental health problem & & \\
\hline No & 108 & 86.4 \\
\hline Yes & 14 & 11.2 \\
\hline No response & 3 & 2.4 \\
\hline & & \\
\hline Mean age (Range: 18-78) & Mean & SD \\
\hline Mean number of children (Range: 1-3) & 37.95 & 14.784 \\
\hline Problem Seriousness (1-10) & 1.38 & .590 \\
\hline
\end{tabular}

Table 3 Multiple regression on public stigma

\begin{tabular}{|c|c|c|c|c|c|}
\hline$N=125$ & $\begin{array}{l}\text { Unstandardized } \\
\text { Coefficients } \\
\text { B }\end{array}$ & $\begin{array}{l}\text { Standard } \\
\text { Error }\end{array}$ & $\begin{array}{l}\text { Standardized } \\
\text { Coefficients } \\
\text { Beta }\end{array}$ & $t$ & $P$ \\
\hline (Constant) & -2.379 & .454 & & -5.237 & $<.001$ \\
\hline $\begin{array}{l}\text { Problem Seriousness (1-10; } \\
10=\text { most serious) }\end{array}$ & .250 & .041 & -.523 & 6.172 & $<.001$ \\
\hline $\begin{array}{l}\text { Attitude toward mental illness } \\
(0-3 ; 0=\text { no stigma) }\end{array}$ & -.656 & .260 & .213 & 2.529 & .013 \\
\hline Patient's Gender ( $0=$ male $)$ & -.332 & .176 & -.156 & -1.880 & .063 \\
\hline $\begin{array}{l}\text { Knowing someone with } \\
\text { mental health problems } \\
(0=\text { no })\end{array}$ & -.100 & .176 & .047 & .569 & .571 \\
\hline $\begin{array}{l}\text { Comorbid with Diabetes } \\
(0=\mathrm{no})\end{array}$ & -.056 & .178 & -.026 & -.316 & .753 \\
\hline
\end{tabular}

$F(5,89)=11.652, P<.001 ; \mathrm{R}^{2}=.40$ 